\title{
DRILLING DOWN ON SMART MANUFACTURING -- ENABLING COMPOSABLE APPS
}

\author{
Boonserm Kulvatunyou, Nenad Ivezic*, KC Morris, Simon Frechette \\ Engineering Laboratory \\ National Institute of Standards and Technology \\ 100 Bureau Drive, Stop 8260, Gaithersburg, MD 20899 U.S.A.
}

(*) Corresponding Author: nivezic@ nist.gov / +1 3019753536

\begin{abstract}
Manufacturing software services provisioned as unbundled "apps" could be significantly more flexible and less expensive to use than the current monolithic manufacturing applications. However, integrating such heterogeneous apps is not a trivial job. National Institute of Standards and Technology (NIST) has initiated a research and development program to advance science and engineering towards the vision of composable SM systems. In April 2016, NIST hosted a workshop, called Drilling down on Smart Manufacturing -- Enabling Composable Apps, to work with industry and academia on needed technical and standards-based solutions. This paper reports on key outcomes of this workshop.
\end{abstract}

Keywords: Smart Manufacturing; manufacturing standards; manufacturing crowd-sourcing; manufacturing architectures

\section{Composable Smart Manufacturing Systems}

Smart Manufacturing (SM) is the term coined to capture the convergence of a number of technological advances applied to manufacturing operations. Those advances include enhanced networking, adaptive automation, cloud services, and data analytics [1,2]. In the factories and supply chains of the future, SM systems will use network-accessible software services to improve performance and increase agility.

That future is vastly different than today, where the software controlling many manufacturing operations is implemented in large, expensive, monolithic applications. These applications are slow to adapt to changing needs, lock users in to single vendor's solutions, and are too expensive for small manufacturers. With SM, this software will be available in small, pay-as-you-go "apps" (i.e., applications focused on a single function, as opposed to large, multi-functional applications) from both incumbent providers and small startups. Manufacturers will access these apps as downloadable components or cloud services. This pay-as-you-go model promises to lower barriers and reduce cost significantly.

As the variety of apps, services, and systems available through this model proliferate, so do the risks associated with using, managing, and integrating them. One way to reduce the risks involves an ecosystem of standards and technologies that enable the composition of these apps, services, and systems. The workshop Drilling down on Smart Manufacturing -- Enabling Composable Apps, organized by NIST and the Open Applications Group Inc. (OAGi), explored the needed foundations for this eco-system.

\section{Workshop Background and Overview}

This was the second such workshop. In the first workshop, Open Cloud Architecture for Smart Manufacturing [3], the open cloud-service platform was recognized as the basis for developing this ecosystem. Figure 1 illustrates the identified standards and technology R\&D issues that hinder both the creation of the ecosystem and the adoption of the new platform. The follow-on workshop, discussed here, addressed the top five R\&D issues through various working sessions, as shown in the figure. These sessions, their objectives, and key outcomes are discussed below. 


\begin{tabular}{|c|c|c|c|}
\hline Workshop Working Session & Potentially Impacts & R\&D Issue & $\begin{array}{c}\text { R\&D Issue } \\
\text { Category }\end{array}$ \\
\hline $\begin{array}{l}\text { SM Systems Model-based Messaging } \\
\text { Standards Development }\end{array}$ & & $\begin{array}{l}\text { Inadequate standards } \\
\text { development processes }\end{array}$ & $\begin{array}{l}\text { Standards } \\
\text { Adoption }\end{array}$ \\
\hline SM Systems Characterization & & Difficult to use standards & \\
\hline SM Standards Capability Analysis & & $\begin{array}{l}\text { Overlapping and unclear } \\
\text { standards capabilities }\end{array}$ & \\
\hline SM Apps \& Service Marketplaces & & Additional standards needed & $\begin{array}{l}\text { Standards } \\
\text { Development }\end{array}$ \\
\hline $\begin{array}{l}\text { Crowdsourcing of Manufacturing } \\
\text { Knowledge }\end{array}$ & & New architecture needed & Architecture \\
\hline
\end{tabular}

Fig. 1: Top issues hindering the adoption of a new open-cloud platform for manufacturing

\subsection{SM model-based messaging standards development}

High-quality messaging standards are essential for SM deployment. These standards are the foundation for improved interoperability among manufacturing systems, increased automation in a manufacturing enterprise, and advanced manufacturing services composition. This vision requires a revolutionary way to register, discover, and compose services based on a shared reference model.

The session's emphasis was on the OAGIS data-exchange messaging standards, which are based on the ISO Core Components paradigm [4]. The session explored approaches to (1) extending these standards, (2) enabling standard reference models, and (3) furthering analysis and synthesis tools that would facilitate both syntax-independent and business-process-first standards. Syntax-independent standards capture semantics of a standard to insulate it from implementation details, which often change during its life-cycle. Participants agreed that a business-process-first strategy, where projects start by identifying business requirements rather than starting with data requirements, would be advantageous. The expected impacts are an increase in standards adoption, more efficient application integration, and, ultimately, a reduction in risks and costs of integration. Three new research goals were identified:

- Common processes for developing and maintaining standards-based, service-oriented integration.

- Tools for developing collaborative and traceable integration standards.

- Methods for discovering, documenting, and sharing context-dependent, standards usage experiences.

\subsection{SM systems characterization}

As the number and kinds of SM technologies increase, manufacturers need tools and guidelines to evaluate and prioritize their investments. This requires (1) methods to characterize both the manufacturers' requirements and the technologies' capabilities, (2) tools for matching requirements to capabilities, (3) methods for assessing a manufacturer's readiness to use the technologies, and (4) standards and measurements to facilitate deployment.

This session focused on classifications of SM technologies and methods for assessing a manufacturers' readiness to use them. Suggested methods included MESA Manufacturing Operations Management Maturity Model [5], the Supply Chain Readiness Level (SCRL) [6], and the NIST Smart Manufacturing System Readiness Level (SMSRL) [7]. Three new research goals were identified:

- Technical means, which may include a reference model, to capture the current state of a manufacturing organization in regards to SM.

- Standards for product definitions and manufacturing processes, SM asset definitions and equipment capabilities, and SM asset security management. 
- Measurement methods to assess a manufacturing system in the form of readiness, capabilities, or maturity levels.

\subsection{SM standards capability analysis}

A key requirement to deploy these emerging SM technologies is the ability to acquire extensive and purposeful information flows and activity flows throughout the enterprise. The ability of disparate systems, however, to exchange, understand, and exploit these flows - especially across product, production, and business life cycles- rests critically on information standards [8]. This session brought standards developers, technology providers, and manufacturing users together to discuss needs, opportunities and challenges for new standards and measurements to accelerate SM technology adoption. The session provided a forum for key stakeholders to review the body of pertinent standards and measurements and to identify gaps and overlaps. The needed research efforts to develop new capabilities were discussed:

- Specification and means for gathering context information at levels 1 and 2 of the ISA-95 manufacturing control architecture [9].

- High-level SM reference architecture, including communication, process, data, and service models to support integration from diverse machines and software vendors.

- Mechanisms for fusing data from diverse sources across domains, lifecycle activities, and vendors.

\subsection{SM apps and service marketplaces}

In this session, the potential of SM apps and service marketplaces were explored. The aim is to work towards shared, secure, open-access infrastructure that is rich in functionality for easier systems integration and composability and a marketplace that can drive technological capability beyond just products by integrating standard services on uncertainty quantification, benchmarking, performance-use metrics, systems modeling, and many more. A special focus was on current technological and other challenges as well as requirements from different stakeholders' (e.g., designers, providers \& users) perspectives. An SM market place will be a sociotechnical system which empowers workers and in which apps are fully integrated with workforce functions.

The session included panel discussions that focused on (1) functions, components and requirements of an SM apps marketplace; (2) systems perspectives within the marketplace; (3) challenges of the marketplace; and (4) essential standards for SM adaptation. The following key areas of research were identified:

- Need for precise vocabularies accessible through multiple viewpoints.

- Technologies for assisting people in manufacturing tasks and workflows.

- Interface standards for equipment and resources to allow app interoperability.

- Market infrastructure and governance (e.g., certification of apps and services) to provide scaled security and confidence.

\subsection{Crowdsourcing of manufacturing knowledge}

Formal knowledge models are necessary components of SM systems. A main challenge in developing such models is an efficient means of eliciting the knowledge from distributed sources. Another challenge involves the formation of a coherent body of knowledge for those sources - a body that can be validated and extended by users. Today, such a body is developed in a centralized, top-down fashion.

This session explored a different approach: a crowd-sourcing approach, from a broad selection of experienced manufacturers. The participants discussed the user expertise needed to use such an approach for gathering manufacturing knowledge. Expert knowledge would be most valuable; but, no one is an expert in all areas of manufacturing. A novel idea based on gaming techniques for soliciting knowledge 
was explored. Most participants thought that it might be useful for gathering basic knowledge. More sophisticated knowledge, however, might require other techniques. The topics discussed included (1) requirements for knowledge capture in SM; (2) approaches for knowledge capture: top-down vs. bottomup vs. middle-out; (3) tools, methods, and standards for knowledge capture for SM; and (4) stakeholders of knowledge models for SM. Some of the identified requirements for the on-going research include:

- Common ontology and definitions in support of the SM marketplace.

- Validation mechanisms for the crowdsourced knowledge models.

- Uniform knowledge-representation that supports a variety of crowdsourcing and knowledge management tools.

\section{Summary and Future Plans}

A new series of workshops was started to foster a shared vision of a new SM platform that will support composable apps and systems. The workshops are attended by representatives from academia, industry, and government agencies, and included participants from the US, Korea, Japan, Mexico, Germany, and Sweden. Realizing the vision requires (1) closing the gaps and removing the overlaps among standards and (2) using those results in the deployment of emerging SM technologies. This paper summarized preliminary outcomes from the sessions at the second workshop in the series. A detailed workshop report, describing an $R \& D$ roadmap is being prepared. In parallel, projects are starting to address key issues with industry-led evaluation. Future workshops will review progress and refresh the roadmap as needed. Participation in the workshops is open and we seek involvement from diverse perspectives.

\section{Acknowledgements and Disclaimer}

The authors acknowledge support from the session chairs of the Drilling down on Smart Manufacturing -- Enabling Composable Apps workshop: Yan Lu, David Noller, Hyunbo Cho, Dennis Brandl, Farhad Ameri, and William Bernstein.

Any mention of commercial products is for information only; it does not imply recommendation or endorsement by NIST.

\section{References}

[1] President's Council of Advisors on Science and Technology, Steering Committee of the Advanced Manufacturing Partnership 2.0 (AMP2.0). Report to the President: Accelerating U.S. Advanced Manufacturing. https://www.whitehouse.gov/sites/default/files/microsites/ostp/PCAST/amp20_report_final.pdf; 2014 [accessed 26.07.16].

[2] Kulvatunyou B, Ivezic N, Srinivasan, V. On architecting and composing engineering information services to enable smart manufacturing. Journal of Computing and Information Science in Engineering. doi: 10.1115/1.4033725. 2016.

[3] Ivezic N, Kulvatunyou B, Lu Y, Lee Y, Lee J, Jones A, et al. NIST Workshop on Open Cloud Architectures for Smart Manufacturing. http://dx.doi.org/10.6028/NIST.IR.8124. 2015. [accessed 26.07.16]

[4] International Standards Organization. ISO 15000-5: 2014 Electronic business extensible markup language (ebXML) - Part 5: Core components specification (CCS), Geneva, Switzerland. 2014.

[5] MESA. MESA MOM Capability Maturity Model V. 1.0. 2016.

[6] Tucker B. SCRL-model for Human Space Flight Operations enterprise supply chain. 2010.

[7] Jung K, Kulvatunyou B, Choi S, and Brundage MP. An Overview of a Smart Manufacturing System Readiness Assessment. Intl. Conf. on Advances in Production Management Systems. In press. 2016.

[8] Lu Y, Morris KC, Frechette S. Current Standards Landscape for Smart Manufacturing Systems. National Institute of Standards and Technology Interagency Report 8107. 2016.

[9] American National Standards Institute. ANSI/ISA-95.00.01-2000, Enterprise-Control System Integration Part 1: Models and Terminology. 2000. 
